\title{
Two-dimensional gel electrophoresis analysis of the leiomyoma interstitial fluid reveals altered protein expression with a possible involvement in pathogenesis
}

\author{
BLENDI URA $^{1}$, FEDERICA SCRIMIN ${ }^{1}$, FABRIZIO ZANCONATI ${ }^{2,6}$, GIORGIO ARRIGONI ${ }^{3,4}$, \\ LORENZO MONASTA $^{1}$, ANDREA ROMANO ${ }^{6}$, RUBINA BANCO ${ }^{1}$, MARINA ZWEYER ${ }^{2}$, \\ DANIELA MILANI ${ }^{5}$ and GIUSEPPE RICCI ${ }^{1,2}$
}

\begin{abstract}
${ }^{1}$ Institute for Maternal and Child Health - IRCCS 'Burlo Garofolo', Trieste; ${ }^{2}$ Department of Medical, Surgery and Health Sciences, University of Trieste, Trieste; ${ }^{3}$ Department of Biomedical Sciences, University of Padua; ${ }^{4}$ Proteomics Center of Padua University, Padua; ${ }^{5}$ Department of Morphology, Surgery and Experimental Medicine, University of Ferrara, Ferrara; ${ }^{6}$ UCO Pathological Anatomy and Histology,

Azienda Ospedaliera-Universitaria Ospedali Riuniti, Trieste, Italy
\end{abstract}

Received November 12, 2014; Accepted December 30, 2014

DOI: $10.3892 / o r .2015 .3827$

\begin{abstract}
Uterine leiomyoma is the most common smooth benign neoplasm. In the present study, we analyzed the global interstitial fluid (IF) profile of leiomyoma vs. normal myometrium to identify protein dysregulation involved in leiomyoma pathogenesis. Two-dimensional gel electrophoresis and mass spectrometry were used to generate and compare the global interstitial fluid profiles of the leiomyoma and of the normal tissue. Two proteins were validated by immunohistochemistry. By comparing the interstitial fluid profile of the leiomyoma with that of the normal myometrium, the levels of seven proteins were found to be significantly different: four structural organization proteins (desmin, prelamin-A/C, transgelin and $\alpha$-actinin-1), an inflammatory response ( $\alpha 1$-antitrypsin), a response to oxidative stress (peroxiredoxin-2), and a folding protein (heat shock $70 \mathrm{kDa}$ protein 1A/1B). Desmin, $\alpha 1$-antitrypsin and peroxiredoxin- 2 were upregulated in the leiomyoma, whereas heat shock $70 \mathrm{kDa}$ protein $1 \mathrm{~A} / 1 \mathrm{~B}$, $\alpha$-actinin-1, prelamin-A/C and transgelin were downregulated. Desmin and $\alpha 1$-antitrypsin were further validated by immunohistochemistry. By identifying proteins with altered expression levels compared to the myometrium from several pathways of the leiomyoma pathogenesis, we found the leiomyoma interstitial fluid to have a characteristic proteomic profile. A better appreciation of the pathophysiology of the disease can be useful in the development of conservative treatments that serve as viable alternatives to hysterectomy.
\end{abstract}

Correspondence to: Dr Blendi Ura, Institute for Maternal and Child Health - IRCCS 'Burlo Garofolo', Via dell'Istria 65, I-34135 Trieste, Italy

E-mail: blendi.ura2006@libero.it

Key words: interstitial fluid, myometrium, leiomyoma, 2-D gel electrophoresis, MALDI-TOF/TOF

\section{Introduction}

Uterine leiomyoma is the most widespread benign neoplasm in women aged 30-50 years (1). Its prevalence based on clinical examination is at $33 \%$, on ultrasound scan at $50 \%$ and on histological examination after hysterectomy at $77 \%$ (2). Due to health problems (pain, but more importantly heavy uterine bleeding), leiomyomas are the most frequent causes of hysterectomy (3).

At present, the interest for more conservative treatment is on the increase as leiomyomas remain under-studied, and the exact molecular pathways involved in their formation have not been clearly understood. Their etiopathogenesis seems multifactorial, and genetic factors and hormonal exposure are relevant factors in the growth of leiomyomas (4).

Tumor growth is strongly dependent on estrogen and progesterone, and both have a mitogenic effect on leiomyoma cells (5). Estrogen and progesterone seem to have a mitogenic effect on leiomyoma cells and to act by influencing (directly and indirectly) other hormones and a large number of growth factors, cytokines and apoptotic factors (6). Clinical and pharmacological studies showed that anti-progestinic or selective progesterone receptor modulators reduce the uterine volume of the leiomyoma (7). Preclinical tests with ulipristal suggested that they inhibit cell proliferation only in leiomyoma cells (8).

Myostatin and activin A can regulate myometrial cell proliferation and are overexpressed in the leiomyoma when compared to the normal myometrium (9). Abnormal extracellular matrix (ECM) protein expression, and increased growth factors, cytokines and chemokines leading to disorganized ECM are involved in the development and growth of uterine leiomyomas (10). Modifications of the ECM, its viscosity and elasticity, may change the intercellular communication by determining an increased mitotic activity (11). Mechanical signals are transmitted by the receptor from the ECM to the cytoskeleton, in order to maintain an isometric state and structural organization of a default (12). RhoA, a small 
GTPase protein, appears to be part of a mechano-regulatory circuit that could modify the interactions between proteins of the cytoskeleton by inducing leiomyoma growth (13). A recent study focusing on different cell lines indicated involvement of the ECM in tumorigenesis (14). The tumor interstitial fluid (TIF) consists of a liquid phase that accumulates inside the tumor interstitium (15). In addition to the group of blood soluble proteins, it contains a large subset of abnormal proteins released by tumor cells through classical secretion, non-classical secretion, membrane protein shedding and secretion via exosomes (16). The proteomic approach has been described for leiomyoma tissue (17) and plasma (18). However, to the best of our knowledge, no study has been conducted on the leiomyoma interstitial fluid (IF). Examination of the IF proteins may be an appropriate way to understand the active modification of the ECM involved in leiomyoma growth.

The aim of the present study was to identify proteins with altered expression in leiomyoma cells when compared to the normal myometrium, possibly involved in the pathogenesis of the leiomyoma. In order to identify proteins specifically regulated in the leiomyoma IF, 10 pairs of normal and leiomyoma tissue samples from individual patients were subjected to twodimensional gel electrophoresis (2-DE) analysis combined with protein identification by MALDI-TOF/TOF mass spectrometry.

\section{Materials and methods}

Tissue samples. Tissue samples were obtained from 10 premenopausal patients who underwent hysterectomy for symptomatic uterine leiomyomas. The procedures complied with the Declaration of Helsinki and were approved by the Review Board of the Institute for Maternal and Child Health - IRCCS 'Burlo Garofolo' of Trieste, Italy. All subjects signed a written informed consent. Two samples were collected from 10 patients: one sample from the central area of the leiomyoma and a second sample from the unaffected myometrium. All the leiomyomas were confirmed histologically as benign ordinary leiomyomas. The mean age of the patients was 45.6 years with a minimum of 40 years and a maximum of 53 years. Clean fresh leiomyoma and myometrium (500 $\mu \mathrm{g}$ each) were washed with sterile PBS at $4^{\circ} \mathrm{C}$ as previously described (16). Tissues were cut into sections of $\sim 1-3 \mathrm{~mm}^{3}$, rinsed in sterile PBS at $4^{\circ} \mathrm{C}$ and placed in sterile Petri dishes with $5 \mathrm{ml}$ sterile PBS. The samples were incubated for $24 \mathrm{~h}$ at $37^{\circ} \mathrm{C}$ in a humidified $\mathrm{CO}_{2}$ incubator. Thereafter, a protease inhibitor mix $(2 \mathrm{mM}$ PMSF, $1 \mathrm{mM}$ benzamidine, $1 \mathrm{mM}$ EDTA, $1 \mathrm{mM}$ iodoacetamide and $10 \mathrm{mM} \mathrm{NaF}$ ) was added and the samples were centrifuged at $2,000 \times \mathrm{g}$ for $30 \mathrm{~min}$ at $4^{\circ} \mathrm{C}$. Approximately $5 \mathrm{ml}$ of supernatant was desalted and concentrated with an Ultrafree-4 centrifugal filter unit with a cut-off molecular weight of $10 \mathrm{kDa}$ at $4,000 \mathrm{xg}$ at $25^{\circ} \mathrm{C}$ until the remaining volume reached 100-200 $\mu$ l. The protein content of the supernatant was determined by the Bradford assay.

Two-dimensional gel electrophoresis. Two hundred micrograms of proteins from each sample were denatured in $150 \mu \mathrm{l}$ of dissolution buffer [ $7 \mathrm{M}$ urea, $2 \mathrm{M}$ thiourea, $4 \%$ CHAPS, $40 \mathrm{mM}$ Tris, $65 \mathrm{mM}$ DTT and 0,24\% Bio-Lyte (3-10)] and a trace of bromophenol blue. The solutions were vortexed at maximum speed several times and kept at room temperature for $1 \mathrm{~h}$.
Seven-centimeter pH 3-10 NL (IPG) Readystrips (Bio-Rad, Hercules, CA, USA) were rehydrated at $50 \mathrm{~V}$ for $12 \mathrm{~h}$ at $20^{\circ} \mathrm{C}$. Isoelectric focusing (IEF) was performed in a protein IEF Cell (Bio-Rad) set to $65,000 \mathrm{Vh}$. After IEF, the IPG strips were equilibrated by serial incubation $(20 \mathrm{~min})$ in equilibration buffer (6 M urea, $2 \% \mathrm{SDS}, 50 \mathrm{mM}$ Tris- $\mathrm{HCl} \mathrm{pH}$ $8.8,30 \%$ glycerol, and $1 \%$ DTT) and in equilibration buffer containing $4 \%$ iodoacetamide instead of DTT. Equilibrated IPG strips were transferred onto a $12.5 \%$ polyacrylamide gel for the second dimension. The second dimension was run on Mini-Protean 3 Cell (200 V constant voltage) for $\sim 40$ min until the bromophenol blue reached the bottom of the gel. After protein fixation for $90 \mathrm{~min}$ in $40 \%$ methanol and $10 \%$ acetic acid, the gels were washed twice for $20 \mathrm{~min}$ in distilled water. The gels were stained for $48 \mathrm{~h}$ with colloidal Coomassie Blue, and excess dye was removed with distilled water. On average, three experimental replicates were performed per sample. Molecular masses were determined by precision protein standard markers (Bio-Rad), covering a range of 10-250 kDa. 2-DE gels were scanned with a Molecular Imager PharosFX System and analyzed using the ProteomeWeaver 4 program (both from Bio-Rad).

Quantification of spot levels, prediction of non-classical secreted protein candidates and biological process. Spot normalization was automatically performed by the software and was based on a normalization algorithm intended for numerical analysis, which did not require any internal standard. For each gel an intensity factor was computed to ensure all normalization factors were as close to one as possible. The matching produced a list of super spots, which represent a certain protein species present in the gel. For the correct matching, each super spot was manually controlled prior to normalization. For each matched pair of gels, the quotient between the pair-matched spot was calculated. The normalization factor was the median of these quotients (ProteomeWeaver 4 program; Bio-Rad).

SecretomeP 2.0 (CBS, Technical University Copenhagen, Denmark) was applied to classify proteins as non-classical secreted in case they did not contain a signal peptide and, at the same time, their $\mathrm{NN}$-score exceeded the normal threshold of 0.5. ExoCarta analyses (NHMRC Biomedical Research Fellow, Bundoora, Australia) were performed to evaluate the number of identified proteins known to be exosomal proteins. Differential proteins distributed in the biological process data were obtained from the Gene Ontology (http://amigo.geneontology.org/rte).

In-gel digestion and MS analysis. Spots from 2-DE were digested with sequencing grade-modified trypsin (Promega, Madison, WI, USA) and analyzed by mass spectrometry, as described by Bertacco et al (19). Briefly, the spots were manually excised from the gels, repeatedly washed with $50 \mathrm{mM}$ $\mathrm{NH}_{4} \mathrm{HCO}_{3}$, shrunk with acetonitrile (ACN) for $20 \mathrm{~min}$ and dried under vacuum. Eight to $10 \mu \mathrm{l}$ of trypsin $(12.5 \mathrm{ng} / \mu \mathrm{l}$ in $50 \mathrm{mM} \mathrm{NH}_{4} \mathrm{HCO}_{3}$ ) were added to each spot and the samples were kept in ice for $30 \mathrm{~min}$ before being incubated overnight at $37^{\circ} \mathrm{C}$. Peptides were then extracted from the gel by three changes of $75 \%$ ACN $/ 0.1 \%$ trifluoroacetic acid (TFA). For MS analysis, the samples were dried under vacuum and suspended in $10 \mu \mathrm{l}$ of $20 \% \mathrm{ACN}$ and $0.1 \%$ TFA. One microliter of the sample was mixed with $1 \mu 1$ of the matrix solution 


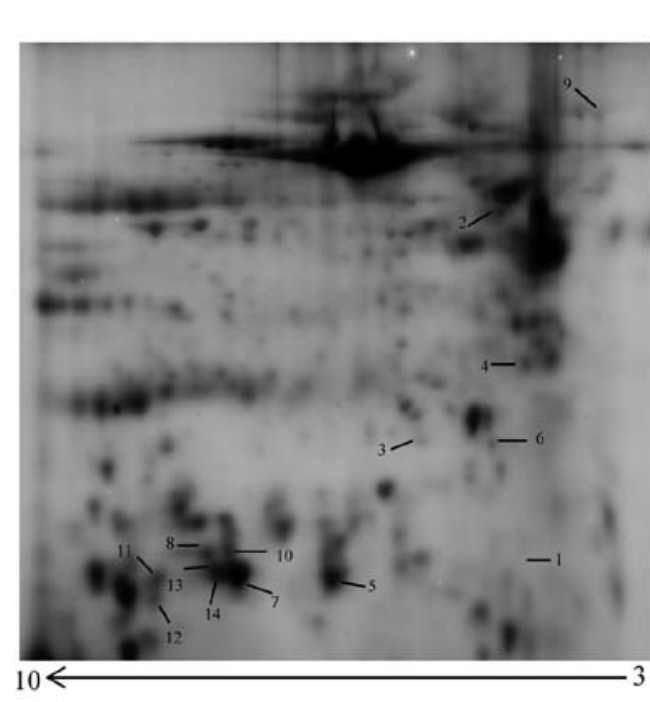

Myometrium

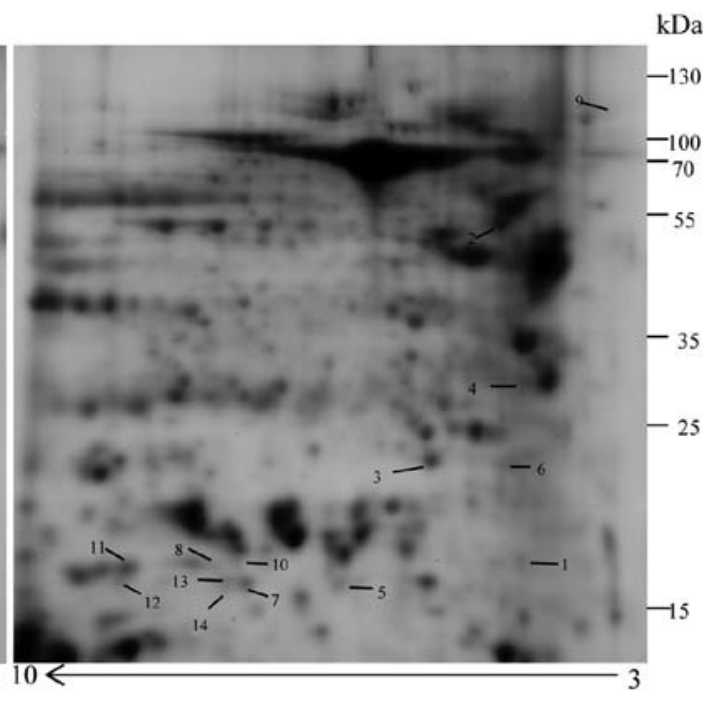

Leiomyoma

Figure 1. Two-dimensional electrophoresis map of normal myometrium and uterine leiomyoma interstitial fluid using immobilized pH gradient 3-10 NL readystrips in the first dimension and $12.5 \%$ polyacrylamide gel in the second dimension. The protein loading was $200 \mu \mathrm{g}$ and the gels were stained with Coomassie colloidal blue.

( $\alpha$-cyano-4-hydroxycinnamic acid, $5 \mathrm{mg} / \mathrm{ml}$ in $70 \% \mathrm{ACN} / 0.1 \%$ TFA). An amount of $0.8 \mu \mathrm{l}$ of the final sample/matrix mixture was spotted onto a 386 wells stainless steel MALDI plate. The samples were analyzed with a MALDI-TOF/TOF 4800 mass spectrometer (AB Sciex, Framingham, MA, USA) operating in a data-dependent mode: a full MS scan (in the range of $900-3000 \mathrm{~m} / \mathrm{z}$ ) was followed by MS/MS scans of the 10 most intense ions. A total of 1,500 and 3,500 laser shots were collected for MS and MS/MS spectra, respectively. Data were converted into Mascot Generic Format (MGF) files using the 4000 Series Explorer software (AB Sciex) and searched using Mascot search engine (version 2.4; Matrix Science, London, UK) against the human section of the Uniprot database (version 2014041688708 entries). Enzyme specificity was set to trypsin with one missed cleavage. Carbamidomethyl cysteine was set as fixed modification and methionine oxidation as variable modification. Tolerance for precursor and fragment ions was set to $50 \mathrm{ppm}$ and $0.3 \mathrm{Da}$, respectively. Proteins were considered identified if $\geq 2$ unique peptides with individual significant score $(\mathrm{P}<0.05)$ were sequenced. A search under the same conditions but against the corresponding randomized database did not return any positive identification.

Immunohistochemistry. Immunohistochemistry was performed, using leiomyoma and myometrial biopsies $(n=10)$ from the same surgical specimen. Fixed and paraffin-embedded leiomyoma and myometrial tissues were deparaffinized and rehydrated using xylene and a graded alcohol, as previously described (20-22). Tissue sections were treated with $3 \%$ hydrogen peroxidase (15 $\mathrm{min}$ at room temperature) followed by incubation for $30 \mathrm{~min}$ at room temperature with 1:100 diluted mouse monoclonal anti-desmin (Thermo Fisher Scientific, Waltham, MA, USA), pre-diluted rabbit polyclonal anti- $\alpha 1$-antitrypsin (Ventana Medical Systems, Tucson, AZ, USA), 1:100 diluted rabbit monoclonal anti-human estrogen receptor (Diagnostic Biosystems) and 1:50 diluted mouse monoclonal anti-human progesterone receptor (Dako). Tissue sections were then incubated for $15 \mathrm{~min}$ at room temperature with ready-to-use HRP-conjugated anti-mouse IgG (Thermo Scientific) for desmin and human progesterone receptor, while HRP conjugated anti-rabbit IgG (Thermo Fisher Scientific) was incubated for $\alpha 1$-antitrypsin and human estrogen receptor. Chromogenic staining was performed with a diaminobenzidine chromogen and counterstaining was performed with hematoxylin. Immunohistochemical slides were examined with a Leica DM 2500 and images were captured using a D-Slight automated digital scanner (Menarini Diagnostics, GrassinaFirenze, Italy) at a magnification of x20 and x40. Positive immunostaining was scored quantitatively and qualitatively by two blinded independent observers. The score ranged from 0 to 3 , where 0 was no staining; 1 , minimal staining; 2 , strong staining and 3 , intense staining.

Statistical analyses. Statistical analyses were carried out with the non-parametric Wilcoxon signed-rank test for paired samples. $\mathrm{P}<0.05$ was considered as being statistically significant. Associations between values of desmin, $\alpha 1$-antitrypsin and progesterone in the leiomyoma and the myometrium were performed with a two-tailed Fisher's exact test. The analyses were conducted with Stata/IC 11.2 for Windows (Stata Corp LP, College Station, TX, USA).

\section{Results}

Two-dimensional electrophoresis map and protein expression levels identified by MALDI-TOF/TOF mass spectrometry. Approximately 600 protein spots were detected in the 2-DE gels for the two types of IF (Fig. 1). After image alignment, background removal, super spot editing, normalization and statistical analysis, 14 protein spots were found to be significantly different in leiomyoma samples as compared to the myometrium. Three of the spots were upregulated ( $>2$-fold) 
Table I. Protein expression levels measured in the leiomyoma and myometrium interstitial fluid as identified by the MALDI-TOF/TOF mass spectrometry.

\begin{tabular}{|c|c|c|c|c|c|c|c|c|}
\hline $\begin{array}{l}\text { Accession } \\
\text { no. }\end{array}$ & $\begin{array}{l}\text { Spot } \\
\text { no. }\end{array}$ & $\begin{array}{c}\text { Protein } \\
\text { description }\end{array}$ & $\begin{array}{c}\text { Sequence } \\
\text { coverage } \\
(\%)\end{array}$ & ExoCarta & $\begin{array}{l}\text { Total } \\
\text { score }\end{array}$ & NN-score & $\mathrm{Mr} / \mathrm{PI}$ & Fold change $^{a}$ \\
\hline
\end{tabular}

Cytoskeletal organization proteins

\begin{tabular}{|c|c|c|c|c|c|c|c|c|c|}
\hline P17661 & 1 & Desmin & 15.96 & NR & 750.25 & 0.64 & $53.5 / 5.27$ & 14 & 0.027 \\
\hline Q01995 & 5 & Transgelin & 9.45 & Yes & 87.64 & 0.56 & $22.6 / 8.84$ & 0.3 & 0.004 \\
\hline $\mathrm{P} 02545$ & 6 & Prelamin-A/C & 8.74 & Yes & 294.65 & 0.07 & $74.1 / 6.84$ & 0.28 & 0.018 \\
\hline Q01995 & 7 & Transgelin & 26.37 & Yes & 264.94 & 0.56 & $22.6 / 8.84$ & 0.28 & 0.02 \\
\hline Q01995 & 8 & Transgelin & 18.41 & Yes & 221.51 & 0.56 & $22.6 / 8.84$ & 0.23 & 0.025 \\
\hline H9KV75 & 9 & $\alpha$-actinin-1 & 10.34 & Yes & 386.07 & 0.38 & $94.8 / 5.69$ & 0.2 & 0.043 \\
\hline Q01995 & 10 & Transgelin & 9.45 & Yes & 87.64 & 0.56 & $22.6 / 8.84$ & 0.18 & 0.001 \\
\hline Q01995 & 11 & Transgelin & 9.45 & Yes & 52.90 & 0.56 & $22.6 / 8.84$ & 0.17 & 0.002 \\
\hline Q01995 & 12 & Transgelin & 23.38 & Yes & 135.97 & 0.56 & $22.6 / 8.84$ & 0.08 & 0.01 \\
\hline Q01995 & 13 & Transgelin & 18.41 & Yes & 172.18 & 0.56 & $22.6 / 8.84$ & 0.07 & 0.005 \\
\hline Q01995 & 14 & Transgelin & 9.45 & Yes & 52.90 & 0.56 & $22.6 / 8.84$ & 0.07 & 0.005 \\
\hline \multicolumn{10}{|c|}{ Inflammatory response } \\
\hline P01009 & 2 & $\alpha 1$-antitrypsin & 13.65 & Yes & 221.74 & 0.85 & $46.7 / 5.47$ & 3 & 0.022 \\
\hline \multicolumn{10}{|c|}{ Response to oxidative stress } \\
\hline P32119 & 3 & Peroxiredoxin-2 & 18.69 & Yes & 314.71 & 0.52 & $21.9 / 5.97$ & 2 & 0.014 \\
\hline \multicolumn{10}{|c|}{ Protein folding } \\
\hline E7EP94 & 4 & $\begin{array}{l}\text { Heat shock } 70 \mathrm{kDa} \\
\text { protein } 1 \mathrm{~A} / 1 \mathrm{~B}\end{array}$ & 3.64 & Yes & 66.49 & 0.28 & $59.8 / 5.6$ & 0.47 & 0.009 \\
\hline
\end{tabular}

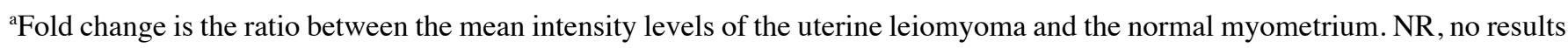
found with the ExoCarta analysis.

and 11 downregulated ( $<0.5$ fold), and corresponded to seven unique proteins identified by MALDI-TOF/TOF and the database search against the human section of the UniProt database.

Differential proteins distributed in the biological process data were obtained from the Gene Ontology: cytoskeletal organization proteins (desmin, prelamin-A/C, transgelin and $\alpha$-actinin-1), an inflammatory response ( $\alpha 1$-antitrypsin), a response to oxidative stress (peroxiredoxin-2), and a protein folding (heat shock $70 \mathrm{kDa}$ protein $1 \mathrm{~A} / 1 \mathrm{~B}$ ).

The SecretomeP 2.0 program revealed that prelamin$\mathrm{A} / \mathrm{C}, \alpha$-actinin-1 and heat shock $70 \mathrm{kDa}$ protein $1 \mathrm{~A} / 1 \mathrm{~B}$ are classically secreted proteins, while $\alpha 1$-antitrypsin, desmin, peroxiredoxin-2 and transgelin are non-classically secreted proteins. Additionally, the ExoCarta analysis confirmed that only desmin, out of the seven identified proteins, could not be classified as an exosomal protein. All the results are presented in Table I. In particular, the three upregulated proteins were desmin, $\alpha 1$-antitrypsin and the antioxidant enzyme peroxiredoxin-2. Of the four downregulated proteins, heat shock $70 \mathrm{kDa}$ protein $1 \mathrm{~A} / 1 \mathrm{~B}, \alpha$-actinin-1, and prelamin-A/C were identified each in a single protein spot, while transgelin was identified in eight different spots (Table I), suggesting the presence of possible alternative splicing and/or isoforms of this protein.

Immunohistochemical analysis of desmin, al-antitrypsin, progesterone and estrogen receptors. To determine the distribution of desmin- and $\alpha 1$-antitrypsin-expressing cells in leiomyoma tissues, an immunohistochemical analysis was performed of 10 individual-matched leiomyomas and normal myometrium tissue specimens. Desmin showed a stronger expression in the leiomyoma than in the myometrium $(\mathrm{P}<0.05)$ (Fig. 2). Positive staining for desmin was located in the cytoplasm of smooth muscle leiomyoma and myometrium cells, while less intense staining of desmin expression was observed in the sclerotic part of the leiomyoma. Taken together, desmin immunohistochemical data confirmed the result of 2-DE analysis. The positivity of $\alpha 1$-antitrypsin in the leiomyoma was also confirmed by immunohistochemistry $(\mathrm{P}<0.05)$. The leiomyomas were positive for $\alpha 1$-antitrypsin, although at different levels of expression. By contrast, the myometrium cells were negative for $\alpha 1$-antitrypsin (Fig. 3). The intensity of $\alpha 1$-antitrypsin staining in the leiomyoma was variable in different areas but positive in all the tested samples, thereby supporting the reliability of the data obtained by the proteomic approach.

Immunohistochemical staining of estrogen and progesterone receptors. The expression of estrogen and progesterone receptors was also analyzed to evaluate any possible association between desmin and $\alpha 1$-antitrypsin and progesterone expression. While no statistically significant differences were observed with respect to expression of nuclear estrogen recep- 

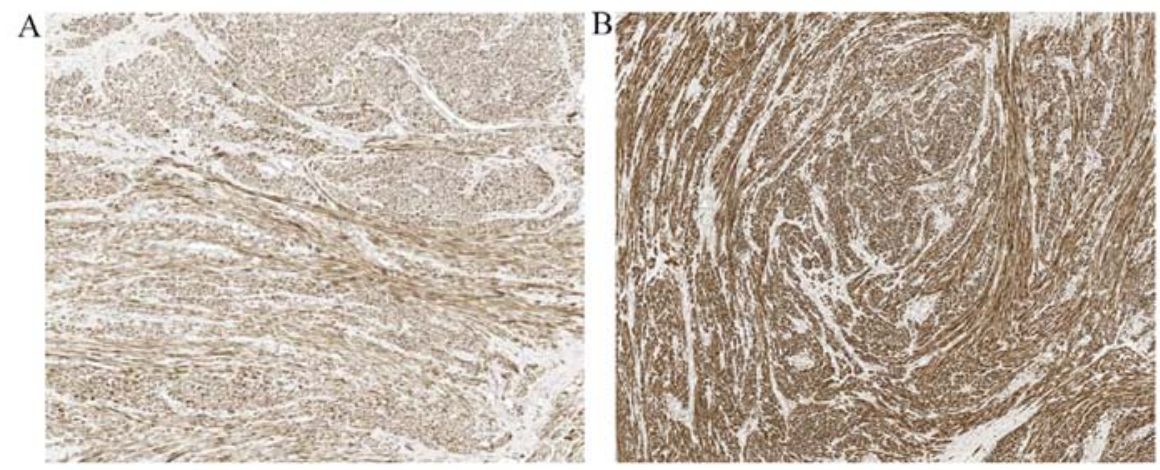

$\mathrm{C}$

Data 1

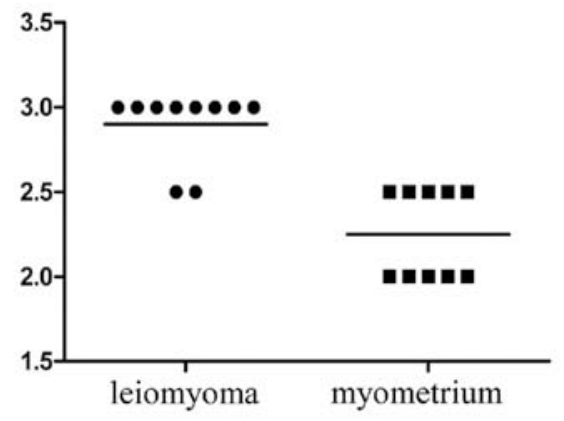

Figure 2. Immunohistochemical staining of desmin in (A) the myometrium and (B) the leiomyoma in smooth muscle cells showing a high magnification portion of these tissues. The leiomyoma shows a diffuse strong stain of desmin, while less intense staining of desmin was observed in the myometrium smooth muscle. Magnification, x20. (C) Statistical analysis of desmin expression reveals an increased expression in the leiomyoma (P<0.05, Wilcoxon sum-rank test). Results are shown as a scatter plot.
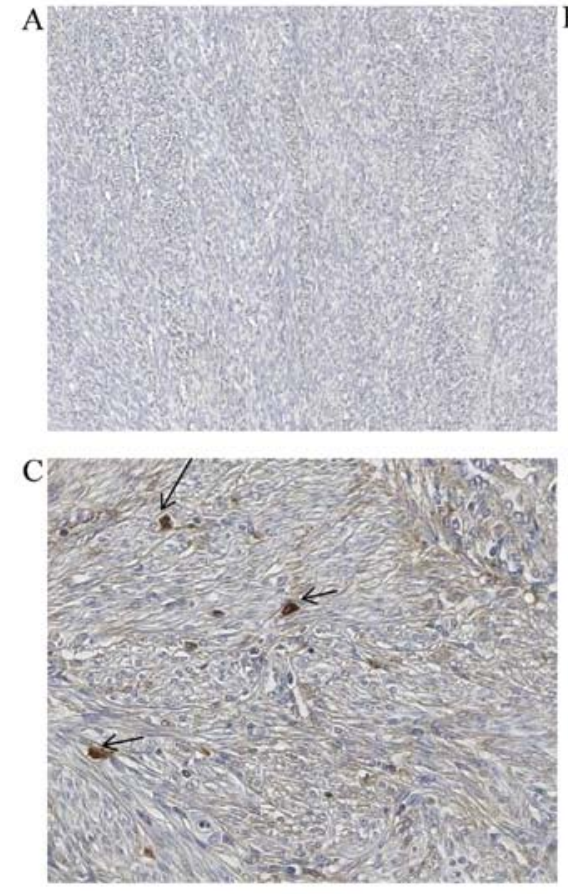

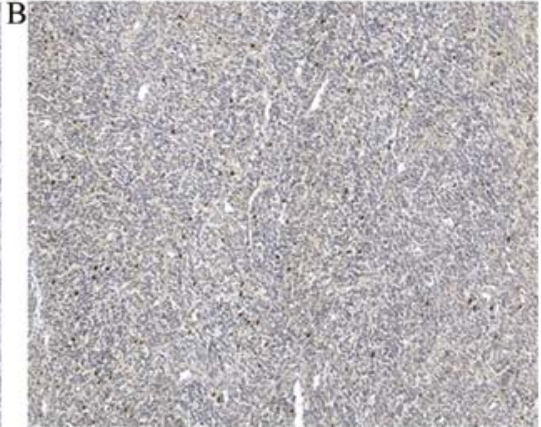

Data 1

D

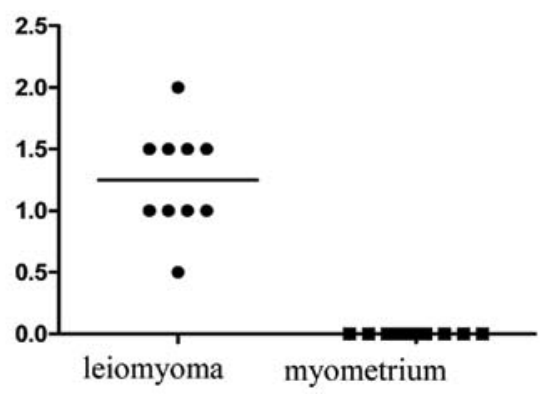

Figure 3. Immunohistochemical staining of $\alpha 1$-antitrypsin in the cytoplasm of (A) myometrium and (B) leiomyoma cells. Magnification, x20. No stain was observed in the myometrium, while in the leiomyoma several brown points were observed indicating cells positive for $\alpha 1$-antitrypsin. (C) $\alpha 1$-antitrypsin positive cells are shown by the black arrows. Magnification, $x 40$. (D) Results are shown as a scatter plot $(\mathrm{P}<0.05)$.

tors between the leiomyoma and the normal myometrium (Fig. 4), progesterone receptor expression was significantly stronger in the nuclei of leiomyoma cells than in normal myometrium (Fig. 5) $(\mathrm{P}<0.05)$. No significant association was found between desmin and progesterone expression, and between $\alpha 1$-antitrypsin and progesterone expression. 

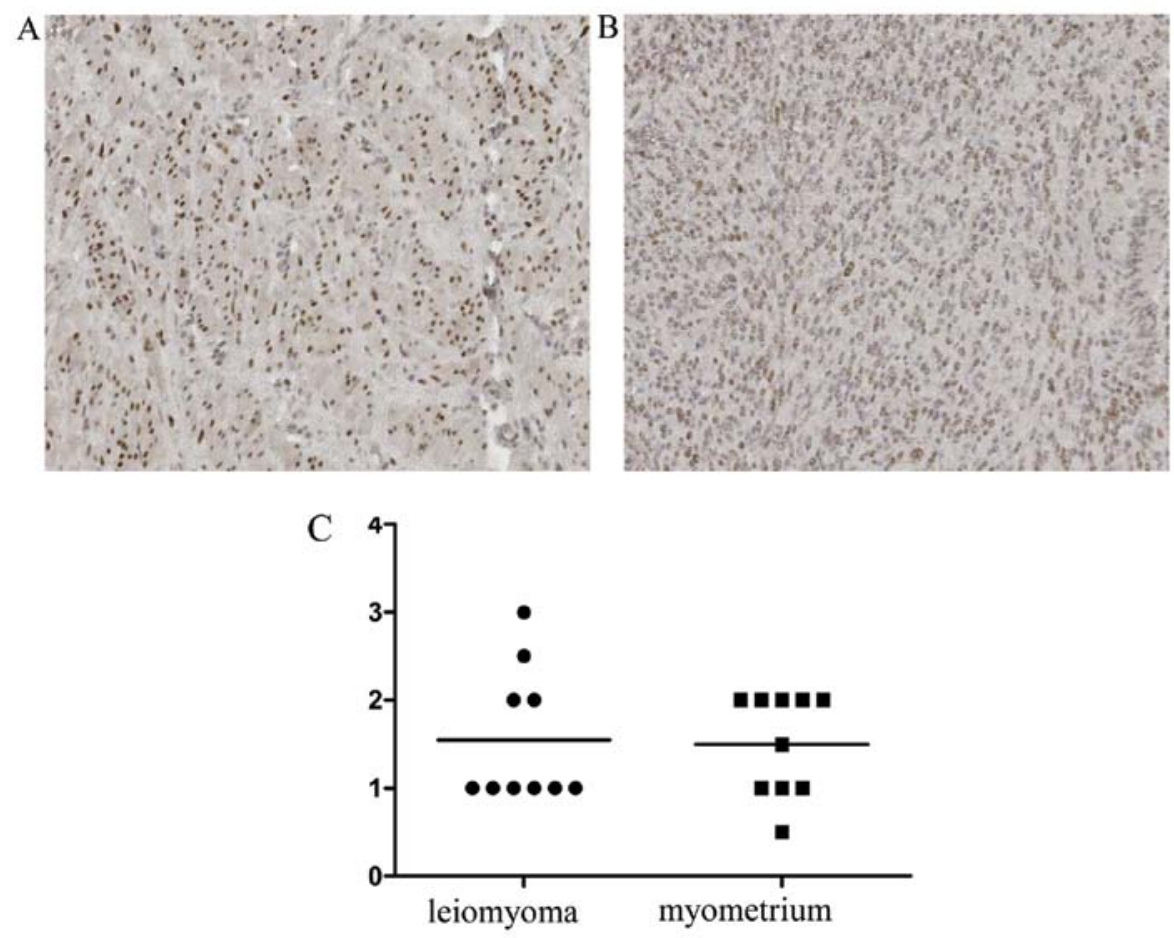

Figure 4. Immunohistochemical staining of estrogen receptor in (A) myometrium and (B) leiomyoma. Magnification, x20. No differences were observed with respect to estrogen receptor expression between the leiomyoma and normal myometrium $(\mathrm{P}=0.8)$. (C) Results are shown as a scatter plot.
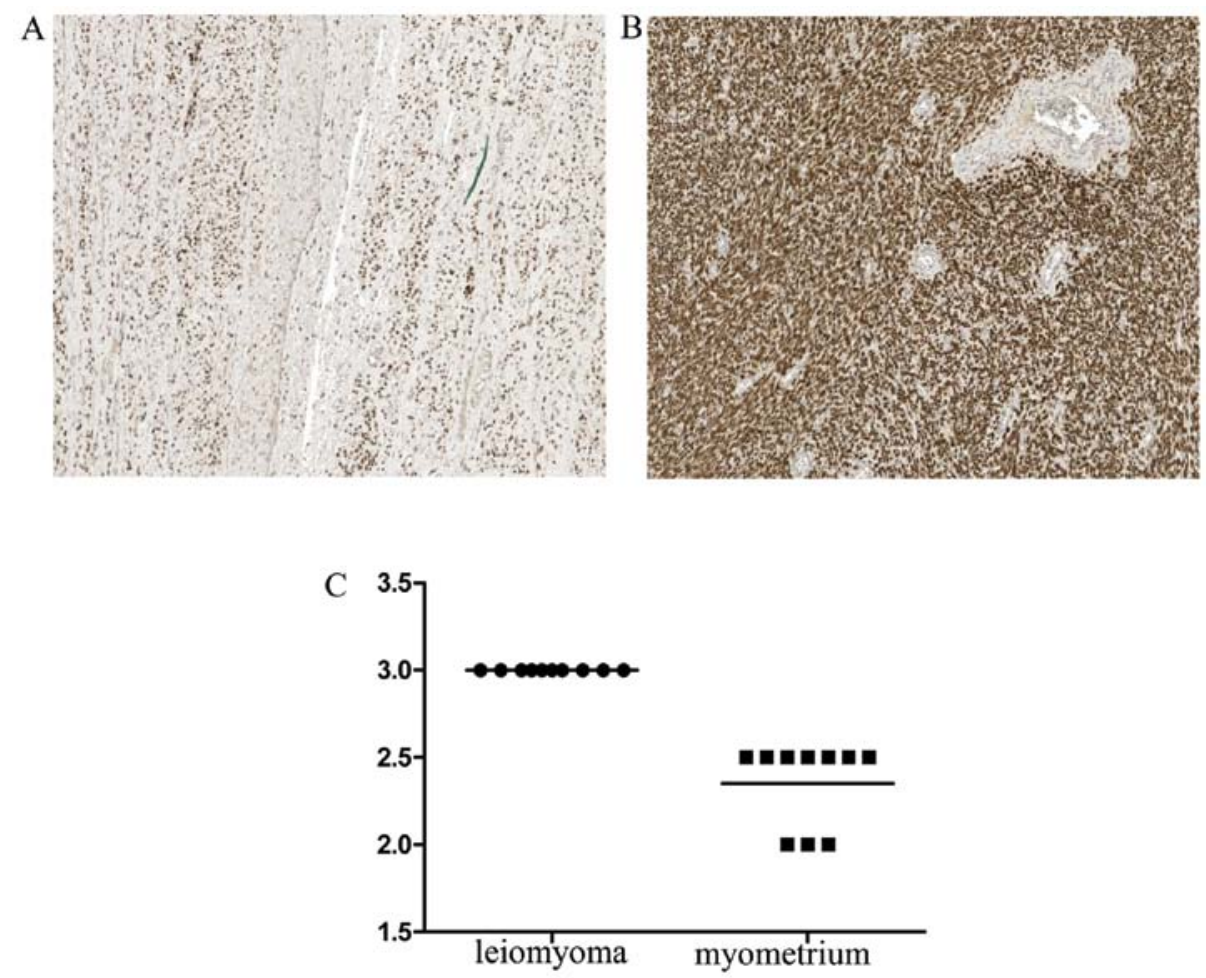

Figure 5. Immunohistochemical staining of receptor of progesterone in (A) myometrium and (B) leiomyoma. Magnification, x20. The leiomyoma shows diffuse strong staining of progesterone, while in the myometrium the intensity of progesterone staining is less intense. (C) Results are shown as a scatter plot $(\mathrm{P}<0.05)$.

\section{Discussion}

In order to analyze the IF profile of leiomyomas in comparison to normal myometrium, a classical proteomic approach based on 2-DE, coupled with mass spectrometry was employed. In many diseases, secreted proteins create conditions that are favorable to the disorder, such as those that promote cancer metastasis (23). Therefore, knowledge of the qualitative and 
quantitative composition of the cell IF may be crucial to understand the biology of cell interaction.

To the best of our knowledge, this is the first proteomics study conducted to compare the IF profiles of the leiomyoma and the normal myometrium. Using this approach we identified seven proteins with a significantly different expression between the leiomyoma and myometrium: $\alpha 1$-antitrypsin, desmin, peroxiredoxin-2 (upregulated in leiomyomas), and prelamin-A/C, transgelin, $\alpha$-actinin-1, and heat shock $70 \mathrm{kDa}$ protein 1A/1B (downregulated in leiomyomas). Two of the upregulated proteins, desmin and $\alpha 1$-antitrypsin (A1AT), found in the leiomyoma IF and further validated by immunohistochemistry, had been previously described at the tissue level of leiomyomas and leiomyosarcomas (17-18,24). Thus, we were able to confirm and expand previous immunohistochemical data, indicating that these proteins were also secreted. In particular, A1AT is a protease inhibitor belonging to the serpin superfamily, which protects tissues from enzymes of inflammatory cells, and whose expression has been associated with survival in leiomyosarcomas (24).

We also demonstrated for the first time an increased level of desmin in the leiomyoma IF. Desmin is a type III intermediate filament expressed by skeletal, smooth, and cardiac muscle tissue (25). The leiomyoma is composed by an abnormal ECM (11). Thus, cells, exposed to different viscoelastic forces, continue to grow and proliferate (26). Secreted desmin can induce an alteration of the mechanotransduction signal from ECM via the transmembrane receptor to the interior of the cell, intervening in the growth of the leiomyoma. This observation is in agreement with the models of Wettschureck et al (27) and Ren et al (28) which demonstrated that ECM proteins transduced signals to activate Rho GTPase and generated cytoskeletal tension leading to possible cell growth.

The last upregulated protein in the IF of the leiomyoma was peroxiredoxin-2 (PRDX2), a member of the antioxidant peroxiredoxin 1-6 enzyme family, which reduced hydrogen peroxide and alkyl hydroperoxides. It has been shown that PRDX2 may have a proliferative effect and plays a role in the matrix production (29). In a previous study, PRDX6, but not PRDX2, was found to be upregulated in the leiomyoma (30). A previous study suggested that hypoxia induces cell damage, act through antioxidant enzymes on quiescent cells inducing proliferation (31). Thus, our current observation of an increased level of PRDX2 in the leiomyoma IF is unprecedented.

The levels of heat shock $70 \mathrm{kDa}$ protein $1 \mathrm{~A} / 1 \mathrm{~B}$ were significantly lower in the leiomyoma IF. It is noteworthy that the anticancer protein TNF-related apoptosis inducing ligand (TRAIL) (32-33) upregulates the HSP70 protein in the leiomyosarcoma cell line, thereby inducing apoptosis (34), which suggests that the increase of HSP70 may play a role in the anticancer response to TRAIL.

Prelamin-A/C can accelerate smooth muscle cell senescence. It disrupts mitosis and induces DNA damage in vascular smooth muscle cells (VSMCs), leading to mitotic failure, genomic instability, and premature senescence (35). Lamins constitute a class of intermediate filaments with structural and functional roles, closely associated with the inner nuclear membrane, nuclear pore complexes and chromatine (36). A decreased expression of lamin $\mathrm{A} / \mathrm{C}$ in low-grade cancer compared with benign epithelium was observed (37). Results of those studies are in agreement with our findings for the leiomyoma and normal myometrium. This protein may have a role in the regulation of cell proliferation (37).

Our observation of a decreased expression of transgelin in the leiomyoma compared to normal myometrium is in agreement with that of other studies (38). Li et al found a reduction of the protein in colorectal cancer cell lines, as transgelin suppresses proliferation and invasion, and induces apoptosis. The decrease of transgelin promotes cell proliferation, promoting the growth of the leiomyoma (38). Consistent with our present findings, an immunohistochemical study on the myometrium and leiomyoma indicates a higher expression of transgelin in the normal myometrium as compared to leiomyoma tissue sections (39).

Another downregulated protein is $\alpha$-actinin-1, an actinbinding protein with multiple roles in different cell types (40), including the connection between the cytoskeleton and diverse signaling pathways (41). $\alpha$-actinin-1 regulates gene expression, thus accelerating ECM accumulation in glomerular disease (40). $\alpha$-actinin-1 has been documented to be a prognostic factor in leiomyosarcoma survival (24).

In conclusion, the 2-DE approach coupled with MS provided a valuable tool for the study of leiomyoma IF. In the present study, we have identified several proteins that were up- or downregulated in the leiomyoma, with possible involvement in the regulation of cell proliferation. Secreted proteins may be involved in several pathogenic pathways, as suggested by other disease models. All the proteins identified as being up- or downregulated in the interstitial fluid may exert a proliferative action on the cells, or even have a synergistic effect. A clear knowledge of leiomyoma growth induction is required to identify new therapeutic targets and to develop new pharmacological approaches for such a widespread condition, which represents the major cause of hysterectomy.

\section{Acknowledgements}

We greatly acknowledge the help of Ms. Tiziana and Mr. Walter for obtaining the samples. Scientific input from Drs Francesco Mangino and Francesco Fanfani is greatly appreciated. We would like to thank Ms. Thomas Marcuzzo and Cristina Bottin for the immunohistochemical analysis and data acquisition.

\section{References}

1. Jacobson GF, Shaber RE, Armstrong MA and Hung YY: Hysterectomy rates for benign indications. Obstet Gynecol 107: 1278-1283, 2006.

2. Lepine LA, Hillis SD, Marchbanks PA, Koonin LM, Morrow B, Kieke BA and Wilcox LS: Hysterectomy surveillance - United States, 1980-1993. MMWR CDC Surveill Summ 46: 1-15, 1997.

3. Bernstein SJ, McGlynn EA, Siu AL, Roth CP, Sherwood MJ, Keesey JW, Kosecoff J, Hicks NR and Brook RH: The appropriateness of hysterectomy. A comparison of care in seven health plans. Health Maintenance Organization Quality of Care Consortium. JAMA 269: 2398-2402, 1993.

4. Okolo S: Incidence, aetiology and epidemiology of uterine fibroids. Best Pract Res Clin Obstet Gynaecol 22: 571-588, 2008.

5. Chegini N, Ma C, Tang XM and Williams RS: Effects of GnRH analogues, 'add-back' steroid therapy, antiestrogen and antiprogestins on leiomyoma and myometrial smooth muscle cell growth and transforming growth factor-beta expression. Mol Hum Reprod 8: 1071-1078, 2002. 
6. Wei T, Geiser AG, Qian HR, Su C, Helvering LM, Kulkarini NH, Shou J, N'Cho M, Bryant HU and Onyia JE: DNA microarray data integration by ortholog gene analysis reveals potential molecular mechanisms of estrogen-dependent growth of human uterine fibroids. BMC Womens Health 7: 5, 2007.

7. Kim JJ and Sefton EC: The role of progesterone signaling in the pathogenesis of uterine leiomyoma. Mol Cell Endocrinol 358 223-231, 2012.

8. Maruo T, Ohara N, Matsuo H, Xu Q, Chen W, Sitruk-Ware R and Johansson ED: Effects of levonorgestrel-releasing IUS and progesterone receptor modulator PRM CDB-2914 on uterine leiomyomas. Contraception 75: S99-103, 2007.

9. Ciarmela P, Bloise E, Gray PC, Carrarelli P, Islam MS, De Pascalis F, Severi FM, Vale W, Castellucci M and Petraglia F: Activin-A and myostatin response and steroid regulation in human myometrium: disruption of their signalling in uterine fibroid. J Clin Endocrinol Metab 96: 755-765, 2011.

10. Ciavattini A, Di Giuseppe J, Stortoni P, Montik N, Giannubilo SR, Litta P, Islam MS, Tranquilli AL, Reis FM and Ciarmela P Uterine fibroids: pathogenesis and interactions with endometrium and endomyometrial junction. Obstet Gynecol Int 2013: 173184, 2013.

11. Norian JM, Owen CM, Taboas J, Korecki C, Tuan R, Malik M, Catherino WH and Segars JH: Characterization of tissue biomechanics and mechanical signaling in uterine leiomyoma. Matrix Biol 31: 57-65, 2012.

12. Alenghat FJ and Ingber DE: Mechanotransduction: all signals point to cytoskeleton, matrix, and integrins. Sci STKE 2002: pe6, 2002.

13. Paszek MJ, Zahir N, Johnson KR, Lakins JN, Rozenberg GI, Gefen A, Reinhart-King CA, Margulies SS, Dembo M, Boettiger D, Hammer DA and Weaver VM: Tensional homeostasis and the malignant phenotype. Cancer Cell 8: 241-254, 2005.

14. Butcher DT, Alliston T and Weaver VM: A tense situation: forcing tumour progression. Nat Rev Cancer 9: 108-122, 2009.

15. Baronzio G, Schwartz L, Kiselevsky M, Guais A, Sanders E, Milanesi G, Baronzio M and Freitas I: Tumor interstitial fluid as modulator of cancer inflammation, thrombosis, immunity and angiogenesis. Anticancer Res 32: 405-414, 2012.

16. Gromov P, Gromova I, Bunkenborg J, Cabezon T, Moreira JM, Timmermans-Wielenga V, Roepstorff P, Rank F and Celis JE: Up-regulated proteins in the fluid bathing the tumour cell microenvironment as potential serological markers for early detection of cancer of the breast. Mol Oncol 4: 65-89, 2010.

17. Lv J, Zhu X, Dong K, Lin Y, Hu Y and Zhu C: Reduced expression of 14-3-3 gamma in uterine leiomyoma as identified by proteomics. Fertil Steril 90: 1892-1898, 2008.

18. Lin CP, Chen YW, Liu WH, Chou HC, Chang YP, Lin ST, Li JM, Jian SF, Lee YR and Chan HL: Proteomic identification of plasma biomarkers in uterine leiomyoma. Mol Biosyst 8: $1136-1145,2012$

19. Bertacco E, Millioni R, Arrigoni G, Faggin E, Iop L, Puato M, Pinna LA, Tessari P, Pauletto P and Rattazzi M: Proteomic analysis of clonal interstitial aortic valve cells acquiring a pro-calcific profile. J Proteome Res 9: 5913-5921, 2010

20. Gugliotta L, Bagnara GP, Catani L, Gaggioli L, Guarini A, Zauli G, Belmonte MM, Lauria F, Macchi S and Tura S: In vivo and in vitro inhibitory effect of alpha-interferon on megakaryocyte colony growth in essential thrombocythaemia. Br J Haematol 71: 177-181, 1989.

21. Secchiero P, Sun D, De Vico AL, Crowley RW, Reitz MS Jr, Zauli G, Lusso P and Gallo RC: Role of the extracellular domain of human herpesvirus 7 glycoprotein $\mathrm{B}$ in virus binding to cell surface heparan sulfate proteoglycans. J Virol 71: 4571-4580, 1997.

22. Zauli G, Secchiero P, Rodella L, Gibellini D, Mirandola P, Mazzoni M, Milani D, Dowd DR, Capitani S and Vitale M: HIV-1 Tat-mediated inhibition of the tyrosine hydroxylase gene expression in dopaminergic neuronal cells. J Biol Chem 275 4159-4165, 2000.

23. Pavlou MP and Diamandis EP: The cancer cell secretome: a good source for discovering biomarkers? J Proteomics 73: 1896-1906, 2010.
24. Suehara Y, Kondo T, Fujii K, Hasegawa T, Kawai A, Seki K, Beppu Y, Nishimura T, Kurosawa H and Hirohashi S: Proteomic signatures corresponding to histological classification and grading of soft-tissue sarcomas. Proteomics 6: 4402-4409, 2006.

25. Bär H, Strelkov SV, Sjöberg G, Aebi U and Herrmann H: The biology of desmin filaments: how do mutations affect their structure, assembly, and organisation? J Struct Biol 148: 137-152, 2004.

26. Peddada SD, Laughlin SK, Miner K, Guyon JP, Haneke K, Vahdat HL, Semelka RC, Kowalik A, Armao D, Davis B and Baird DD: Growth of uterine leiomyomata among premenopausal black and white women. Proc Natl Acad Sci USA 105: 19887-19892, 2008.

27. Wettschureck $\mathrm{N}$ and Offermanns S: Rho/Rho-kinase mediated signaling in physiology and pathophysiology. J Mol Med (Berl) 80: 629-638, 2002.

28. Ren XD, Kiosses WB and Schwartz MA: Regulation of the small GTP-binding protein Rho by cell adhesion and the cytoskeleton. EMBO J 18: 578-585, 1999 .

29. Kubota D, Mukaihara K, Yoshida A, Tsuda H, Kawai A and Kondo T: Proteomics study of open biopsy samples identifies peroxiredoxin 2 as a predictive biomarker of response to induction chemotherapy in osteosarcoma. J Proteomics 91: 393-404, 2013.

30. Bae SM, Kim YW, Lee JM, Namkoong SE, Kim CK and Ahn WS: Expression profiling of the cellular processes in uterine leiomyomas: omic approaches and IGF-2 association with leiomyosarcomas. Cancer Res Treat 36: 31-42, 2004.

31. Mesquita FS, Dyer SN, Heinrich DA, Bulun SE, Marsh EE and Nowak RA: Reactive oxygen species mediate mitogenic growth factor signaling pathways in human leiomyoma smooth muscle cells. Biol Reprod 82: 341-351, 2010.

32. Secchiero P and Zauli G: Tumor-necrosis-factor-related apoptosis-inducing ligand and the regulation of hematopoiesis. Curr Opin Hematol 15: 42-48, 2008

33. Zauli G, Melloni E, Capitani S and Secchiero P: Role of full-length osteoprotegerin in tumor cell biology. Cell Mol Life Sci 66: 841-851, 2009.

34. Karlisch C, Harati K, Chromik AM, Bulut D, Klein-Hitpass L, Goertz O, Hirsch T, Lehnhardt M, Uhl W and Daigeler A: Effects of TRAIL and taurolidine on apoptosis and proliferation in human rhabdomyosarcoma, leiomyosarcoma and epithelioid cell sarcoma. Int J Oncol 42: 945-956, 2013.

35. De Vos WH, Houben F, Hoebe RA, Hennekam R, van Engelen B, Manders EM, Ramaekers FC, Broers JL and Van Oostveldt P: Increased plasticity of the nuclear envelope and hypermobility of telomeres due to the loss of A-type lamins. Biochim Biophys Acta 1800: 448-458, 2010.

36. Ragnauth CD, Warren DT, Liu Y, McNair R, Tajsic T, Figg N, Shroff R, Skepper J and Shanahan CM: Prelamin A acts to accelerate smooth muscle cell senescence and is a novel biomarker of human vascular aging. Circulation 121: 2200-2210, 2010.

37. Kong L, Schäfer G, Bu H, Zhang Y, Zhang Y and Klocker H: Lamin $\mathrm{A} / \mathrm{C}$ protein is overexpressed in tissue-invading prostate cancer and promotes prostate cancer cell growth, migration and invasion through the PI3K/AKT/PTEN pathway. Carcinogenesis 33: 751-759, 2012.

38. Li Q, Shi R, Wang Y and Niu X: TAGLN suppresses proliferation and invasion, and induces apoptosis of colorectal carcinoma cells. Tumour Biol 34: 505-513, 2013.

39. Robin YM1, Penel N, Pérot G, Neuville A, Vélasco V, Ranchère-Vince D, Terrier $\mathrm{P}$ and Coindre JM: Transgelin is a novel marker of smooth muscle differentiation that improves diagnostic accuracy of leiomyosarcomas: a comparative immunohistochemical reappraisal of myogenic markers in $900 \mathrm{soft}$ tissue tumors. Mod Pathol 26: 502-510, 2013.

40. Yang C and Glass WF II: Expression of alpha-actinin-1 in human glomerular mesangial cells in vivo and in vitro. Exp Biol Med (Maywood) 233: 689-693, 2008.

41. Otey CA and Carpen O: Alpha-actinin revisited: a fresh look at an old player. Cell Motil Cytoskeleton 58: 104-111, 2004. 